\title{
Las cooperativas de viviendas en régimen de cesión de uso: ¿una alternativa real a la vivienda en propiedad y en alquiler en España? ${ }^{1}$
}

\author{
Héctor Simón Moreno² \\ Recibido: 14 de diciembre de 2018 / Aceptado: 4 de octubre de 2019 / Publicado: 13 de mayo de 2020
}

Resumen. La crisis financiera internacional, motivada por la expansión de la vivienda en propiedad y la falta de regulación de los préstamos hipotecarios irresponsables, ha afectado de manera relevante a algunos países europeos, como España, en particular en el acceso a una vivienda asequible en propiedad o en alquiler. Esto ha motivado el auge del denominado co-housing o vivienda colaborativa como una vía novedosa para acceder a una vivienda, que en España se ha implementado principalmente gracias a las cooperativas de viviendas en régimen de cesión de uso. El presente trabajo explora de qué manera este modelo puede constituir una alternativa a las tenencias inmobiliarias tradicionales en España, la vivienda en propiedad y en alquiler, es decir, si puede crear un tercer mercado de tenencia inmobiliaria otorgando la debida seguridad jurídica, flexibilidad y asequibilidad o se trata de una vía alternativa que, por el momento, no puede generalizarse. Para ello se abordan y se analizan los principales problemas que se detectan en la actualidad partiendo de su configuración legal en el ámbito estatal y autonómico, con algunas referencias al derecho comparado.

Palabras clave: Derecho a la vivienda; Vivienda colaborativa; Acceso a la vivienda; Tenencias intermedias; Cooperativas.

Claves Econlit: K11; R31; K25.

[en] Housing cooperatives on assignment of use: a real alternative to homeownership and tenancy in Spain?

Abstract. The international financial crisis, fueled by the expansion of homeownership and the lack of regulation of irresponsible mortgage lending, has significantly affected some European countries, such as Spain, in particular on the access to affordable housing in homeownership or tenancy. This has triggered the rise of the so-called co-housing or collaborative housing as a novel way to access housing, which in Spain has been implemented mainly thanks to housing cooperatives on assignment of use. This paper explores how this model can be an alternative to traditional land tenures in Spain, homeownership and tenancy, that is, if it can create a third real estate market providing enough legal security, flexibility and affordability or it is an alternative way that, for the time being, cannot be generalized. In order to do so, the main problems that are currently detected are addressed and analysed based on their legal configuration at the state and regional levels with some references to comparative law.

Keywords: Right to housing; Collaborative housing; Housing access; Intermediate tenures; Cession of use; Cooperatives.

Sumario. 1. Introducción. 2. Los problemas de las cooperativas de viviendas en régimen de cesión de uso como vía principal de implementación del co-housing en España. 3. Las cooperativas de viviendas en régimen de cesión de uso: ¿una alternativa a la vivienda en propiedad o en alquiler? 4. A modo de conclusión. 5. Referencias bibliográficas.

Cómo citar: Simón Moreno, H. (2020) Las cooperativas de viviendas en régimen de cesión de uso: ¿una alternativa real a la vivienda en propiedad y en alquiler en España?. REVESCO. Revista de Estudios Cooperativos, vol. 134, e69165. https://dx.doi.org/10.5209/REVE.69165.

1 Este trabajo ha sido posible gracias a la estancia de investigación en la National University of Ireland, Galway, durante el período comprendido entre el 1 de marzo y el 31 de agosto de 2018, financiada por el Ministerio de Educación, Cultura y Deportes en el marco del Programa "José Castillejo" para la movilidad de jóvenes doctores 2017. Este trabajo también se enmarca dentro del Proyecto sobre "Vivienda colaborativa" concedido en el marco de convocatoria 2017 de Proyectos de I+D correspondientes al Programa Estatal de Fomento de la Investigación Científica y Técnica de Excelencia, Subprograma estatal de generación de conocimiento (2018-2020; DER2017-84726-C3-1-P).

2 Universidad Rovira i Virgili, España

Dirección de correo electrónico: hector.simon@urv.cat 


\section{Introducción}

La crisis económica internacional ha demostrado que la dicotomía dominio-alquiler, tal y como viene configurada en nuestro sistema jurídico, no está dando una respuesta óptima a las necesidades de vivienda de las familias españolas (Nasarre Aznar y Simón Moreno, 2013). En este contexto, la búsqueda de nuevas formas de tenencia inmobiliaria puede articularse por diversas vías. La primera es fomentando el denominado collaborative housing o vivienda colaborativa, un término que engloba una variedad de supuestos (community-led, resident-led, participative housing o co-housing) en los que una pluralidad de personas se auto-organiza para la provisión de vivienda (Czischke, 2018). En este modelo prima la naturaleza colaborativa de las relaciones que los residentes tienen entre sí, así como la importancia de la calidad de vida, la sostenibilidad ambiental, el contacto social y la implicación de sus integrantes, si bien la crisis financiera internacional ha llevado a incluir nuevos valores en este modelo como la asequibilidad y la inclusión social. La segunda vía es adaptando instituciones seculares del Derecho civil, como el derecho de propiedad o el arrendamiento, a las nuevas necesidades socioeconómicas ${ }^{3}$.

Un ejemplo de vivienda colaborativa de interés para el presente trabajo es el co-housing, cuyo nacimiento (como concepto) se remonta a Dinamarca en los años sesenta ${ }^{4}$ y se caracteriza por una serie de notas comunes (Chiodelli y Baglione, 2014; López de la Cruz y Sánchez, 2017; y López de la Cruz y VázquezPastor Jiménez, 2015). En primer lugar, en el co-housing existen, por un lado, espacios privados de carácter residencial sobre los que los residentes ostentan un derecho de naturaleza real u obligacional y, por otro, espacios e instalaciones comunes cuya calidad y cantidad dependen de las preferencias y de la capacidad financiera de sus miembros. Ejemplos de estos últimos elementos son la cocina, el comedor, la lavandería, la sala de reuniones, la biblioteca o el espacio de juego para niños. En segundo lugar, existen normas de naturaleza privada (por ejemplo, unos estatutos) que garantizan el normal funcionamiento de la comunidad, que cuenta con la participación y el compromiso activo de sus miembros. En tercer lugar, los propios integrantes de la comunidad son los que deciden las personas físicas o jurídicas (que pueden tener una naturaleza privada o pública) que pueden acceder a formar parte de la misma. Finalmente, en el co-housing cobra importancia una serie de valores, como la solidaridad, la inclusión, el activismo social, el apoyo mutuo o la sostenibilidad ambiental.

El co-housing se ha implementado en España ${ }^{5}$ siguiendo principalmente el modelo cooperativista (Etxezarreta, Cano y Merino, 2018), que de hecho ofrece varias posibilidades más allá del co-housing (Etxezarreta y Merino, 2013) ${ }^{6}$. Estas cooperativas, que se inspiran en el modelo danés Andel, mantienen la propiedad de las viviendas cuyo uso se cede a los socios que la integran. La elección de esta opción frente a otras formas jurídicas o societarias, como la propiedad horizontal ${ }^{7}$ o las sociedades ${ }^{8}$, se debe a la manera de

Un ejemplo en este segundo caso es la implementación de la propiedad compartida y la propiedad temporal en Cataluña gracias a la Ley 19/2015, de 29 de julio, de incorporación de la propiedad temporal y de la propiedad compartida al libro quinto del Código civil de Cataluña (BOE 8 septiembre 2015, núm. 215, p. 79039). El BOE es accesible en www.boe.es. Sobre estas figuras, ver Nasarre Aznar, 2017, in toto.

Ver sobre los orígenes del co-housing Viela Castranado, 2018.

Otros países, como Francia, también han adoptado el modelo de cooperativa de vivienda en cesión de uso en el Code de la construction et de l'habitation, modificado por la Ley 2014-366, de 24 de marzo, pour l'accès au logement et un urbanisme rénové (ALUR) (última versión disponible en https://www.legifrance.gouv.fr, última visita 23 de noviembre de 2018), que reguló les coopératives d'habitants (arts. L201-1 y siguientes) posibilitando que la cooperativa (que retiene la propiedad de las viviendas) pueda ceder a sus socios el disfrute de la vivienda como residencia principal mediante un derecho de uso. La evolución del co-housing o habitat participatif en Francia puede encontrarse en Bresson y Denèfle, 2015. Por el contrario, la articulación del co-housing a través del cooperativismo necesita fomentarse en Polonia por los poderes públicos debido a los problemas de supervivencia de la propia normativa de cooperativas (Coudroy de Lille, 2015).

6 Por ejemplo, la cooperativa puede servir para la autoconstrucción o rehabilitación de viviendas, la autoconstrucción de viviendas y posterior adjudicación a los socios una vez se liquida la cooperativa (que ha sido el modelo predominante en España), o puede mantenerse (una vez finalizada dicha construcción y adjudicación) para la gestión de los elementos comunes de la propiedad horizontal. Las cooperativas también pueden constituirse específicamente para la gestión de estos elementos (por ejemplo, servicios).

La inadecuación del régimen de propiedad horizontal se debe a su particular configuración jurídica, que busca conseguir la máxima utilidad individual del elemento privativo, la vivienda, de manera que los elementos comunes tienen un carácter accesorio o instrumental y no están diseñados ordinariamente para la vida en comunidad de sus residentes. Sobre la preeminencia de la utilidad del elemento privativo reflexiona De Castro Vítores, 2008. Viela Castranado lo expresa en términos parecidos: "la propiedad horizontal busca proteger, regular y evitar los conflictos de los distintos miembros de la comunidad de propietarios; la regulación del cohousing debe buscar, proteger y definir a la comunidad, frente a terceros" (Viela Castranado, 2018). Es precisamente la solidaridad entre los integrantes de la cooperativa, la puesta en común de los recursos, el deseo de responsabilizarse cada uno por su vivienda y los valores que inspiran la cooperativa (como la cooperación y los valores medioambientales) los aspectos diferenciales de las cooperativas de vivienda francesas respecto a la propiedad horizontal y otras formas de tenencia, como el alquiler social (Bresson y Denèfle, 2015). Además, la realidad muestra en este sentido que la participación de los propietarios en la vida en comunidad es escasa: sólo un $10 \%$ acude regularmente a las reuniones de la comunidad, y el porcentaje de asistencia es inferior al $50 \%$ en el $63 \%$ de las convocatorias (de acuerdo con el Estudio "Vecinos en Comunidad" (2016), realizado por Mutua de Propietarios en colaboración con ICEA. Un resumen puede encontrarse en: https://blog.mutuadepropietarios.es/solo-10-los-vecinos-acude-siempre-las-reunionessu-comunidad/ (última visita 23 de noviembre de 2018).

8 Es cierto que la cooperativa es al mismo tiempo un fenómeno asociativo y una empresa (tal y como la define la Declaración de la Alianza Cooperativa Internacional -https://www.ica.coop/es, última visita 23 de noviembre de 2018-, la cooperativa es "Una asociación autónoma de personas que se han unido de forma voluntaria para satisfacer sus necesidades y aspiraciones económicas, sociales y culturales en común mediante una empresa de propiedad conjunta y de gestión democrática") en tanto que supone la organización de una actividad económica para 
tomar las decisiones y a los principios que rigen esta forma societaria. En efecto, nos referimos a una serie de valores y de principios que rigen naturalmente el funcionamiento de las cooperativas como la autoayuda, la autorresponsabilidad, la democracia, la igualdad, la equidad y la solidaridad, el control democrático de la cooperativa por sus miembros y el sentimiento de comunidad ${ }^{9}$. Por estos motivos, las decisiones se toman de manera conjunta desde el inicio del proyecto ${ }^{10}$, la sostenibilidad y la eficiencia energética son unos valores recurrentes que lo inspiran y es un modelo que, en principio, favorece la vida en comunidad y facilita el acceso a una vivienda con un modelo no especulativo ${ }^{11}$.

La cuestión que aborda el presente trabajo es en qué medida las cooperativas de viviendas en régimen de cesión de uso pueden ser una alternativa por derecho propio a las tenencias de vivienda tradicionales en España, estas son, la vivienda en propiedad y en alquiler ${ }^{12}$. Para ello deberían ofrecer a sus potenciales usuarios la debida estabilidad, flexibilidad, asequibilidad y seguridad jurídica en la tenencia, por ejemplo, a la hora de tener que renegociar o no las condiciones con el oferente cada cierto plazo de tiempo o de poder cambiar de lugar de residencia con flexibilidad. De esta forma, y con referencias al derecho comparado, se identifican en el segundo apartado los principales problemas que presentan estas cooperativas en la actualidad, en particular el régimen jurídico dual de la cooperativa, la financiación del proyecto, el rol de este modelo en nuestro estado del bienestar y su potencial "replicabilidad". En el apartado tercero se reflexiona sobre estas cuestiones y se concluye finalmente sobre si las cooperativas de viviendas en régimen de cesión de uso pueden crear un mercado de vivienda alternativo a la propiedad y el alquiler.

\section{Los problemas de las cooperativas de viviendas en régimen de cesión de uso como vía principal de implementación del co-housing en España}

\subsection{El régimen jurídico de la cooperativa. Una normativa insuficiente}

La Ley estatal de cooperativas ${ }^{13}$ y las diversas leyes autonómicas ${ }^{14}$ regulan los aspectos relativos a la constitución y funcionamiento de las cooperativas y dedican algunos preceptos, específicamente, a las cooperativas de viviendas. Así, se prevé de forma general el régimen de los estatutos, la condición de socios y su responsabilidad ante el impago de deudas, los órganos de gobierno de la cooperativa y la posibilidad de ceder el uso de la vivienda al socio de la cooperativa mediante cualquier título admitido en Derecho (art. 89.3 Ley estatal 27/1999). Lo mismo tiene lugar en la legislación autonómica, que básicamente reproduce el contenido de la legislación estatal con alguna excepción, como la ley de cooperativas catalana que parece dar una cobertura específica al co-housing sin prever no obstante un régimen específico ${ }^{15}$. Por lo tanto, el modelo co-housing, articulado a través de una cooperativa de viviendas en régimen de cesión de uso, tiene plena cabida en la legislación estatal y autonómica, si bien la doctrina ha criticado, con razón, la ausencia de un marco específico en la normativa vigente para articular este modelo (Viela, 2018).

prestar servicios (Chuliá, 2012), pero no es una empresa capitalista stricto sensu donde las decisiones y las retribuciones (dividendos), fruto de la presencia del empresario como núcleo central del proceso productivo, tienen en consideración el capital aportado (Martínez Charterina, 2016).

9 De acuerdo con los valores y principios cooperativos de la Federación de Cooperativas Alianza Cooperativa Internacional.

10 Se trata de un proceso bottom up (de abajo a arriba), como demuestra la experiencia del proyecto Can Batlló de la Cooperativa La Borda (http://www.laborda.coop/es/proyecto/can-batllo/, última visita 23 de noviembre de 2018), donde la toma de decisiones tiene lugar de manera conjunta mediante una asamblea (Gallart, 2014).

11 En el modelo destinado a las personas mayores (senior co-housing), por ejemplo, los factores diferenciales son el apoyo común, el impacto social y cultural, la adaptación de los hogares y el entorno a las necesidades de cada residente, la cultura del reciclaje, la sostenibilidad, el aprendizaje de decidir conjuntamente y conscientemente, la optimización de recursos y el abaratamiento de todos los costes de los servicios (Vives Barceló, 2016).

12 La primera representaba un $76,7 \%$ en 2017 , mientras que la segunda alrededor de un $17 \%$. Fuente: INE. Hogares por régimen de tenencia de la vivienda y CCAA (http://www.ine.es/jaxiT3/Datos.htm?t=4566, última visita 23 de noviembre de 2018).

13 Arts. 89 y siguientes de la Ley 27/1999, de 16 de julio (BOE 17 julio 1999, núm. 170, p. 27027).

14 (Por orden cronológico): Arts. 122 y ss. de la Ley 12/2015, de 9 de julio (Cataluña); art. 91 del Decreto Legislativo 2/2015, de 15 de mayo (DOCV 20 mayo 2015, núm. 7529, p. 14741)(Comunidad Valenciana); arts. 84 y ss. del Decreto Legislativo 2/2014, de 29 de agosto (BO Aragón 9 septiembre 2014, núm. 176, p. 30528) (Aragón); arts. 113 y ss. de la Ley 6/2013, de 6 de noviembre (BO Cantabria 18 noviembre 2013 , núm. 221, p. 37619) (Cantabria); arts. 97 y ss. de la Ley 14/2011, de 23 de diciembre (BO Junta de Andalucía 31 diciembre 2011, núm. 255, p. 22)(Andalucía); arts. 135 y ss. de la Ley 11/2010, de 4 de noviembre (BOE 12 febrero 2011, núm. 37, p. 15225)(Castilla-La Mancha); arts. 153 y ss. de la Ley 4/2010, de 29 de junio (BO del Principado de Asturias 12 julio 2010, núm. 160) (Asturias); art. 68 de la Ley Foral 14/2006, de 11 de diciembre (BOE 4 enero 2007, núm. 4, p. 562) (Navarra); arts. 112 y ss. de la Ley 8/2006, de 16 de noviembre (BOE 9 mayo 2007, núm. 111, p. 19906) (Murcia); arts. 117 y ss. de la Ley 4/2002, de 11 de abril (BOE 15 mayo 2002, núm. 116, p. 17540)(Castilla y León); arts. 119 y ss. de la Ley 4/2001, de 2 de julio (BOE 19 julio 2001, núm. 172, p. 26098)(La Rioja); arts. 144 y ss. de la Ley 4/1999, de 30 de marzo (BOE 2 junio 1999, núm. 131, p. 20841) (Madrid); arts. 120 y ss. de la Ley 5/1998, de 18 de diciembre (DO Galicia 30 diciembre 1998, núm. 251, p. 13768) (Galicia); arts. 134 y ss. de la Ley 2/1998, de 26 de marzo (BOE 29 mayo 1998, núm. 128, p. 17777) (Extremadura); y arts. 114 y ss. de la Ley 4/1993, de 24 de junio (BO País Vasco 19 julio 1993, núm. 135, p. 6863) (País Vasco).

15 Ver en este sentido el art. 122.3 Ley 12/2015: "Las cooperativas de viviendas también pueden tener por objeto la rehabilitación de viviendas, locales y edificaciones e instalaciones complementarias para destinarlos a sus socios, así como la construcción de viviendas para cederlas a los socios mediante el régimen de uso y disfrute, bien para uso habitual y permanente, bien para descanso o vacaciones, o destinadas a residencias para personas mayores o con discapacidad" (la cursiva es nuestra). 
En efecto, la ausencia de una regulación específica fuerza a las cooperativas de viviendas en régimen de cesión de uso a adaptar las disposiciones legales a las vicisitudes propias de su funcionamiento. Así se desprende de los estatutos que rigen estas cooperativas ${ }^{16}$ (tomando como punto de partida la Ley estatal 27/1999). Ejemplos de esta adaptación son el necesario cumplimiento de una serie de requisitos para formar parte de la cooperativa, que decide la admisión del aspirante teniendo en cuenta si ya tiene una vivienda en propiedad (en cuyo caso debe alquilarla a un precio no especulativo) o una edad determinada (como ocurre en el senior co-housing), que desarrolla lo dispuesto en el art. 13 Ley 27/1999. Los estatutos también concretan los supuestos de baja voluntaria y justificada del socio cooperativista desarrollando lo dispuesto en el art. 17 Ley 27/1999. Otros ejemplos son las obligaciones económicas de los socios respecto a la adquisición de la condición de socio y posterior pago mensual por el uso de la vivienda (que concreta la obligación general del art. 15.2.e) Ley 27/1999) y la cesión del uso de la vivienda, limitándose los estatutos a reproducir lo previsto en la ley ${ }^{17}$.

Precisamente, la naturaleza jurídica del derecho por el cual la cooperativa cede al socio el uso de la vivienda es esencial para conocer su posición jurídica (derechos y obligaciones, etc.). Sin embargo, la normativa sobre cooperativas no lo define ni lo regula en profundidad. La razón radica en que los aspectos relativos al derecho de propiedad y a la cesión del uso de las viviendas se rigen por la legislación civil y no por la legislación de cooperativas (Lambea Rueda, 2012).

Pues bien, los potenciales derechos reales que pueden otorgarle el uso exclusivo y excluyente de la vivienda (el arrendamiento urbano no nos parece hoy por hoy una opción realista ${ }^{18}$ ) son el de usufructo, el de uso o el de habitación, pero lo cierto es que no han conseguido crear un tercer mercado de vivienda alternativo a la propiedad y el alquiler. Esto es un indicativo de los problemas de adaptar su régimen jurídico al acceso a una vivienda ${ }^{19}$.

Por ejemplo, el uso del derecho real de usufructo, que es naturalmente disponible por cualquier título (art. 561-9 del Código Civil de Cataluña, en adelante, CCC, y art. 480 del Código Civil, en adelante, CC) y permite obtener todos los rendimientos posibles del bien sobre el que recae sin limitaciones, es decir, sin estar restringidos a los que sean necesarios para su titular (arts. $471 \mathrm{CC}$ y $561-6 \mathrm{CCC})^{20}$, se ha circunscrito básicamente al derecho de sucesiones y en las donaciones y no ha tenido un impacto relevante en el acceso a la vivienda. La razón es que no es un derecho que esté destinado a lograr un equilibrio entre los derechos y las obligaciones de las partes como sucede, por ejemplo, en el arrendamiento (Molina Roig, 2014).

Por su parte, el derecho real de uso se encuentra regulado en los arts. 562-1 y siguientes CCC y en los arts. 523 y siguientes CC, que lo configuran como un derecho naturalmente personalísimo, no susceptible de ser transmitido ni hipotecado y que se limita ordinariamente a las necesidades de su titular y de las personas que convivan con él. Lo mismo puede predicarse del derecho real de habitación (arts. 523 y siguientes CC y 562-1 y siguientes CCC), que se diferencia del derecho real de uso en varios aspectos. En primer lugar, únicamente otorga el uso (no el disfrute) de un espacio de la vivienda (la habitación) y de los elementos comunes necesarios para satisfacer sus necesidades. Y, en segundo lugar, sus titulares sólo pueden serlo personas físicas (no jurídicas) y sólo deben satisfacer aquellos gastos que sean individualizables. Con todo, el

16 Se han tomado como ejemplos los estatutos de la cooperativa La Borda y Trabensol (disponibles en http://www.laborda.coop/es/proyecto/documentos/ y http://trabensol.org/wp-content/uploads/2013/03/ESTATUTOS-TRABENSOL.pdf, respectivamente, última visita 23 de noviembre de 2018).

17 A nivel autonómico puede destacarse la iniciativa de la Ley de vivienda del País Vasco (Ley 3/2015, de 18 de junio, BOE 13 julio 2015 , núm. 166, p. 57907), que prevé la posibilidad de que las asociaciones sin ánimo de lucro puedan ceder el uso de los inmuebles de su propiedad a los socios mediante un derecho de uso, "que tendrá carácter indefinido y será también transmisible «mortis causa» en sus propios términos y contenidos" (Apartado 4 Disposición Adicional $3^{\mathrm{a}}$ ). Esta previsión no aclara, de nuevo, la naturaleza jurídica de este derecho.

18 En efecto, el contrato de arrendamiento no se acomodaría a las necesidades de las cooperativas de viviendas ya que si bien parte de la regulación de la Ley de Arrendamientos Urbanos de 1994 (BOE 25 noviembre 1994, núm. 282, p. 36219, en adelante, LAU) podría aplicarse al régimen del co-housing, como el mantenimiento, el uso y los gastos sobre la vivienda, existen aspectos imperativos como el régimen de duración del contrato o el derecho de desistimiento (que se recogen con la finalidad de encontrar una regulación equilibrada entre los intereses contrapuestos de propietarios y arrendatarios) que plantean problemas de compatibilidad con el régimen de la cooperativa. A estos problemas podría añadirse la imposibilidad de concertar contratos de duración indeterminada en el tiempo (art. 9 LAU) y los supuestos de subrogación legal en caso desistimiento, abandono o muerte del titular del contrato o la atribución del derecho de uso en los casos de separación, divorcio o nulidad del matrimonio (art. 12, 15 y 16 LAU), que pueden plantear un conflicto con la necesidad de que el arrendatario tenga la condición de socio cooperativista para poder tener derecho a usar la vivienda (López de la Cruz y Vázquez-Pastor Jiménez, 2018).

19 De esta manera, se ha afirmado que "Hoy por hoy, si bien nuestro ordenamiento jurídico prevé algunos mecanismos (esencialmente, derechos reales como el uso, la habitación, el usufructo o el derecho de superficie; pero también contratos como el arrendamiento con opción de compra o, incluso, situaciones de concurrencia de dos titularidades de distinta naturaleza como el censo enfitéutico) que podrían ser utilizados como tenencias intermedias, la realidad es que ninguno de ellos ha servido para cohesionar realmente una tercera opción —a la propiedad y al alquiler - para acceder a una vivienda" (Nasarre Aznar y Simón Moreno, 2013). Para un análisis de las ventajas y los inconvenientes del uso de los derechos reales de habitación, uso y usufructo en las cooperativas de viviendas desde la óptica del Código Civil español, ver Lambea Rueda, 2012a. Y para un análisis de los derechos reales de uso y habitación para habitar parcialmente una vivienda, Simón Moreno, 2011.

20 En el mismo sentido, la doctrina defiende el uso de los derechos reales de uso y habitación como alternativa al arrendamiento ya que en estos derechos se puede controlar mejor el abuso que en el usufructo (ya que se prevé el abuso grave como causa específica de extinción, art. 529 CC) y porque el contenido del usufructo es excesivamente amplio (tantos las facultades de disfrute como el poder de disposición), ver Lacruz Mantecón, 2018, 339 y ss. 
margen para modificar el título constitutivo permitiría la constitución de ambos derechos a título gratuito u oneroso en el CC, así como su hipotecabilidad (STS de 26 de julio de $2001^{21}$ ).

Si se pone en relación las previsiones más relevantes de los estatutos de las cooperativas de viviendas que regulan la cesión de su uso de la vivienda con la regulación civil de estos derechos, se aprecian aspectos que sí que se acomodan a la legislación civil ${ }^{22}$ y algunas contradicciones. Ejemplos de estas últimas son:

a) La duración indefinida del derecho, dado que la muerte del usuario determina no sólo la pérdida de la condición de socio sino también la ordinaria extinción del derecho (que es necesariamente temporal ${ }^{23}$ ), por lo que el término es incertus quando, certus an (se sabe que llegará, aunque no se tenga la certeza de cuándo).

b) La previsión de que el derecho de uso sólo se extinguirá en caso de baja de la persona socia o si esta es expulsada de la cooperativa, ya que existen otras causas generales de extinción de los derechos reales como la destrucción de la vivienda (arts. 513.1.5 CC y 561-16.1.d) CCC). Además, debería entenderse que la pérdida de la condición de socio operaría como una condición resolutoria (art. 513.1.2 CC).

c) La imposibilidad de que los titulares del derecho puedan constituir cargas y gravámenes, como una hipoteca, o transformar el régimen de tenencia a la propiedad o similar (como un alquiler con opción de compra), lo que implicaría que tiene una naturaleza personalísima (intuitu personae, es decir, que se concede únicamente al socio por su condición de tal) a pesar de que, al mismo tiempo, tiene una naturaleza patrimonial al satisfacer el usuario una cuota por el uso de la vivienda, lo que convierte al derecho de uso en un tertium genus (un derecho con elementos que sugieren un carácter personalísimo $\mathrm{y}$, a su vez, patrimonial).

d) La facultad del socio titular del derecho de usar los espacios y equipamientos comunitarios de acuerdo con el Reglamento de Régimen Interno, si bien el derecho real de uso recae únicamente sobre la vivienda y sus anexos.

En nuestra opinión, es cierto que el principio de autonomía de la voluntad (arts. 1255 CC y 111-6 CCC) permite modificar el alcance y el contenido de los derechos reales, de manera que tanto el derecho real de uso como el de usufructo pueden configurarse de forma similar en cuanto al objeto (vivienda), duración (vitalicia), alcance (uso y/o disfrute de la vivienda), naturaleza onerosa o gratuita y régimen de derechos y obligaciones, llegando por lo tanto a confundirse ${ }^{24}$. Sin embargo, las cooperativas deberían escoger aquel derecho que naturalmente se adaptase más a sus necesidades sin llegar al extremo de desnaturalizarlo, en este caso el derecho real de uso, que recae naturalmente sobre toda la vivienda, se limita a las necesidades de su titular y de los que convivan con él (básicamente, residir en ella) y no concede la posibilidad de disponer del bien. Con todo, el carácter oneroso desvirtúa en cierto modo el carácter intuitu personae de este derecho, que sería, por lo tanto, un tertium genus.

En el último apartado se incide en los aspectos que deberían tenerse en consideración para una regulación específica del derecho real de uso en el ámbito del co-housing.

\subsection{Los aspectos financieros de las cooperativas}

En cuanto a la financiación y la puesta en marcha de las cooperativas de viviendas en régimen de cesión de uso (Scanlon y Fernández Arrigoitia, 2015), en el co-housing puede existir un constructor que se encargue de la adquisición del suelo y la construcción de las viviendas con base en las instrucciones de los impulsores del modelo, o bien estos últimos pueden financiar por ellos mismos estos costes (como ocurre en Dinamarca y en el Reino Unido con el first new-build cohousing scheme). También es posible que el constructor lleve a

21 ECLI:ES:TS:2001:6626 (el ECLI puede consultarse en http://www.poderjudicial.es/search/indexAN.jsp\#). Ver en este sentido Fernández Campos, 1999. En el mismo sentido, el CCC prevé específicamente que el derecho real de uso pueda recaer específicamente sobre una vivienda (art. 562-7 CCC) y que pueda configurarse con un carácter patrimonial o personal, es decir, puede transmitirse y gravarse si lo consiente su propietario (art. 562-4.1 CCC). La duración se presume vitalicia si se ha constituido a favor de una persona física, Sentencia Audiencia Provincial de Tarragona (Sección Primera) de 15 julio de 2011 (ECLI:ES:APT:2011:1139).

22 Así, el socio debe destinar la vivienda cooperativa única y exclusivamente a residencia habitual y permanente, lo que puede pactarse en el título de constitución, y debe hacerse cargo de todas aquellas obras de mantenimiento y conservación ordinarias y extraordinarias y las de mejora ordinarias que sean necesarias para la conservación en buen estado (se establecen mecanismos para que el socio pueda recuperar el importe de las obras extraordinarias), así como de la rehabilitación de los elementos de uso privativo de la vivienda. Este régimen concuerda parcialmente con el previsto para el derecho real de uso por aplicación subsidiaria de la normativa del usufructo (art. 528 CC y 561-12 CCC), que distingue entre las obras de conservación y reparación ordinarias (a cargo del titular del derecho) y las extraordinarias (a cargo del propietario) (arts. 500 y 501 CC y 561-12 CCC).

23 Ver la Sentencia del Tribunal Superior de Justicia de Cataluña de 19 de octubre de 2017 (ECLI:ES:TSJCAT:2017:8462) y la Sentencia del Tribunal Supremo de 4 de febrero de 1983 (RJ 19831803).

24 En relación a la normativa catalana, Lucas Esteve defiende en cuanto a la modalidad no alimenticia del derecho real de uso que "Els drets d'ús i d'habitació constituïts en aquesta modalitat queden desproveïts de l'element característic que els diferenciava fins ara de l'usdefruit i es produeix una aproximació, si no confusió, entre aquests drets reals" (Lucas Esteve, 2014a). 
cabo el proyecto sin la participación directa de los usuarios (como sucede en Estados Unidos), a quienes luego se les ofrece la oportunidad de formar parte de la comunidad. Los costes, por otra parte, no necesariamente deben superiores: mientras que los elementos comunes pueden incrementar el coste (por ejemplo, si van dirigidos a las personas mayores), otros pueden rebajarlo (por ejemplo, el menor espacio requerido en los elementos privativos o el uso común de algunos servicios o la autoconstrucción de determinados elementos comunes). Además, existen riesgos que tienen más presencia que en la construcción tradicional tanto en la fase de formación del grupo y de elaboración del diseño como en el proceso de construcción. Ejemplos son el riesgo de abandono del proyecto, la incertidumbre sobre el momento de finalización y la dificultad, una vez finalizada la construcción, de encontrar usuarios.

La experiencia de la cooperativa La Borda (Cabré y Andrés, 2018) muestra que las cooperativas siguen un modelo de autoconstrucción y que priorizan a los profesionales o empresas que pertenecen a la economía social y a los que son miembros de la cooperativa o forman parte de su programa de voluntariado. Esta experiencia acredita también que la búsqueda de financiación es un problema recurrente en las experiencias co-housing, y que la aproximación bottom up ha permitido reducir los costes. Con todo, también se ha puesto de manifiesto la necesaria implicación de la Administración, de la que depende en gran medida la sostenibilidad del modelo. En el mismo sentido, en Francia (Devaux, 2017) la vivienda colaborativa (habitat participatif) presenta problemas de financiación dado que se financia con un $20 \%$ de recursos propios y las entidades bancarias son reticentes a financiar si no se pueden hipotecar individualmente las distintas viviendas que disfrutan los usuarios. La adquisición de suelo también es un tema recurrente en el Reino Unido (Scanlon y Fernández Arrigoitia, 2015).

En definitiva, los modelos co-housing presentan en Europa problemas similares durante el proceso de planificación, entre los que destacan la obtención de suelo, los permisos urbanísticos y la financiación (Tummers, 2016). La situación en España se analiza a continuación.

\subsubsection{La obtención de suelo y los permisos urbanísticos}

En relación a la obtención de suelo, el apoyo principal de las entidades locales en España se traduce en la cesión de suelo de titularidad municipal a la cooperativa gracias a un derecho real de superficie, como ha sido el caso de la cooperativa La Borda ${ }^{25}$, Trabensol o Profuturo (Zaragoza Pascual, 2013). En otros casos, como en la cooperativa Entrepatios, la adquisición del suelo se ha realizado de manera privada con fondos propios $^{26}$. El derecho de superficie, que se regula tanto a nivel estatal (arts. 53 y siguientes del Real Decreto Legislativo 7/2015 ${ }^{27}$ ) como catalán (arts. 564-1 y siguientes CCC), permite que su titular se convierta en el propietario temporal de lo que se construya o edifique (o de lo ya construido o edificado) en suelo ajeno, mientras que el cedente mantiene su propiedad. Al finalizar el período pactado, que no puede ser superior a los 99 años, la propiedad de lo construido revierte gratuitamente al propietario del suelo a no ser que se haya pactado lo contrario.

Algunas entidades locales y comunidades autónomas apuestan decididamente por el derecho de superficie en sus políticas de vivienda. Un ejemplo en el primer caso es Barcelona, que destina el $20 \%$ de las nuevas construcciones a derechos de superficie gracias a que se fomenta específicamente el uso de este instrumento en las cooperativas de viviendas en régimen de cesión de uso $^{28}$, y en el segundo la Comunidad Valenciana ${ }^{29}$. El uso de este derecho para la cesión de suelo municipal con la finalidad de construcción de viviendas de protección oficial plantea algunos problemas (Nasarre Aznar y Simón Moreno, 2013), por ejemplo la posición jurídica de los propietarios de las viviendas durante la vigencia del derecho (por ejemplo, ¿se extingue el derecho si se destruye la vivienda o se puede volver a construir?¡cómo se articula la subrogación del adquirente en la hipoteca del promotor? ¿son realmente propietarios a efectos de la constitución de una comunidad de propietarios?). Con todo, el derecho de superficie se presenta como una fórmula que permite a las cooperativas de viviendas en régimen de cesión de uso disminuir los costes de financiación al no tener que adquirir la propiedad del suelo. Además, es un derecho que puede hipotecarse e inscribirse en el Registro de la Propiedad. Otras potenciales fórmulas, como las tenencias intermedias, se analizan posteriormente en el

25 http://www.laborda.coop/es/proyecto/financiacion/ (última visita 23 de noviembre de 2018).

26 https://www.entrepatios.org/2018/07/02/nos-hemos-hipotecado/ (última visita 23 de noviembre de 2018)

27 Real Decreto Legislativo 7/2015, de 30 de octubre, por el que se aprueba el texto refundido de la Ley de Suelo y Rehabilitación Urbana_BOE 31 octubre 2015, núm. 261, p. 103232).

28 Ver en este sentido el Plan para el derecho a la vivienda de Barcelona 2016-2025, Resumen ejecutivo, Barcelona, septiembre de $2016,69$. Disponible en: http://habitatge.barcelona/sites/default/files/documents/plan por el derecho a la vivienda resumen ejecutivo 0.pdf, última visita 23 de noviembre de 2018).

29 Fecovi, La entidad representativa del cooperativismo de viviendas valenciano apuesta por el modelo de la colaboración público-privada, 18/6/2018 (https://fecovi.es/la-entidad-representativa-del-cooperativismo-de-viviendas-valenciano-apuesta-por-el-modelo-de-la-colaboracionpublico-privada/, última visita 23 de noviembre de 2018). 
presente trabajo.

En relación a los permisos urbanísticos, la legislación urbanística no apoya específicamente el fenómeno de la vivienda colaborativa (por ejemplo, no recibe un tratamiento específico en el RDL 7/2015 más allá de la reserva de suelo para vivienda sujeta a un régimen de protección pública). En el País Vasco (Mogollón García y Fernández Cubero, 2016), por ejemplo, el desarrollo del co-housing no es sencillo dado que el proceso de reclasificación de suelos de no urbanizable a urbanizable puede conllevar cierto tiempo, y, además, la normativa no tiene una regulación específica de este modelo ${ }^{30}$.

\subsubsection{Las fuentes de financiación}

En segundo lugar, de la experiencia de la cooperativa La Borda se desprende que las aportaciones de los socios que habitarán las viviendas representan un $20 \%$ de la financiación necesaria.

De hecho, la aportación inicial de los socios puede ser considerable y oscilar entre los 15.000 (La Borda) y los 40.000 euros (Entrepatios ${ }^{31}$ ), así como el coste de las distintas mensualidades (de 650 euros en Entrepatios). En Alemania la aportación inicial ronda los 35.000 euros para una vivienda de $70 \mathrm{~m} 2^{32}$. Es por esta razón que las cooperativas intergeneracionales tienen menos éxito, aunque se prevé en los estatutos de las cooperativas que el pago mensual pueda reducirse a largo plazo una vez se amortice el préstamo hipotecario que ha financiado la construcción de las viviendas. Desde la perspectiva de los jóvenes españoles entre 15 y 24 años (Muñoz Fernández, 2017) ${ }^{33}$, su tasa de desempleo supera el $40 \%$ y la tasa de temporalidad de sus contratos de trabajo se sitúa en el 72,6\%, una de las más altas de la UE (Ministerio de Empleo y Seguridad Social, 2017), lo que les dificulta acceder a una vivienda en propiedad o en alquiler. De hecho, el acceso a una vivienda en propiedad entre la población de 16 a 29 años ha disminuido de un 54,6\% el 2008 a un $28,4 \%$ en $2016^{34}$, siendo el principal problema el importe de la entrada inicial, que asciende a 2,2 veces su ingreso anual. Todo ello ha llevado a los jóvenes a optar por la vivienda en alquiler, cuyo coste se ha encarecido no obstante representando en 2017 un 48,3\% de los ingresos de un hogar joven y un 85,4\% para una persona joven asalariada ${ }^{35}$. Y desde la perspectiva de las personas mayores, el ingreso en la cooperativa puede depender en ocasiones de la transmisión previa de la vivienda en propiedad en la que reside para hacer frente a los costes iniciales ${ }^{36}$.

En cuanto al resto de la financiación necesaria, esta proviene de la emisión de títulos participativos (29\%), préstamos por parte de la banca ética (35\%) y subvenciones, que sólo representan un 3\%. En este sentido, el art. 54 Ley 27/1999 permite a la cooperativa emitir obligaciones y títulos participativos, y el Real Decreto-ley 7/1996 $6^{37}$ los denominados préstamos participativos. Ambos darán derecho a una remuneración, que deberá estar en función de la evolución de la actividad de la cooperativa. El principal hándicap tanto de los títulos como de los préstamos participativos es la preferencia crediticia de sus titulares. Al ser jurídicamente préstamos ( $c f r$. STS de 13 de julio de $2011^{38}$ en cuanto a los títulos participativos), sus titulares no intervienen en la toma de decisiones de la cooperativa ni tienen control sobre el capital social. Además, su consideración como deuda subordinada implica que su titular recuperará su inversión después de los créditos $\operatorname{ordinarios}^{39} \mathrm{y}$, en particular, de los créditos hipotecarios que se hayan desembolsado para financiar la construcción. En cuanto a la banca ética, se trata de un modelo que se ha implementado con éxito en España y es clave para la financiación de los proyectos de cooperativas de viviendas en cesión de uso (Segura y

30 De hecho, el proyecto 'La Fábrica de la Transición', que pretende restaurar y convertir la Fábrica situada en El Catllar (Tarragona) en un espacio de coworking y vivienda cooperativa en cesión de uso, sólo ha sido posible gracias a una modificación previa de la normativa urbanística. Fuente: Andreu Vera 2/9/2018, Coworking y vivienda cooperativa en una fábrica abandonada de El Catllar (https://www.diaridetarragona.com/tarragona/Coworking-y-vivienda-cooperativa-en-una-fabrica-abandonada-de-El-Catllar-20180902-0017.html, última visita 23 de noviembre de 2018 ).

31 Para un piso de $70 \mathrm{~m}^{2}$, más unos $20 \mathrm{~m}^{2}$ de espacios comunes, https://www.entrepatios.org.

32 Ver http://communityhousing.hkcss.org.hk/sites/default/files/share/files/German-sharing-powerpoint-2.pdf (última visita 23 de noviembre de 2018).

33 El autor concluye en su estudio que "Son básicamente las condiciones sociolaborales existentes, como la elevada tasa de paro juvenil, la precariedad laboral y los bajos salarios, que ha provocado una reducción de la renta percibida, la que afecta principalmente a la capacidad de compra y de pago de la juventud. El autor también aboga, con razón, por buscar soluciones estructurales y no coyunturales a estos problemas.

34 Fuente: INE, Hogares por régimen de tenencia de la vivienda y edad y sexo de la persona de referencia (www.ine.es).

35 Aunque el coste de acceso a la vivienda sea inferior en la compra (un 34,4\%), el estudio del Consejo de la Juventud de España concluye que "tanto en el caso de la compra como del alquiler, el acceso a la vivienda se haga prácticamente inviable en el caso de las personas jóvenes asalariadas en solitario y muy difícil en el caso de los hogares jóvenes" (Consejo de la Juventud de España, 2017).

36 Atendiendo al índice de vivienda en propiedad de las personas mayores, "resulta más que viable iniciar con éxito un proyecto de cohousing, con la necesidad de poca ayuda financiera (probablemente con la ayuda de un crédito puente, que en un corto plazo de tiempo sería cancelado tras la venta de su anterior vivienda)" (Etxezarreta, Cano y Merino, 2018).

37 Regulados en el art. 20 del Real Decreto-ley 7/1996, de 7 de junio, de Medidas urgentes de carácter fiscal y de fomento y liberalización de la actividad económica (BOE 8 junio 1996, núm. 139, p. 18977).

38 ECLI:ES:TS:2011:5545.

39 Ver en cuanto a los títulos participativos Pastor Sempere, 2006; y respecto a los préstamos participativos Sánchez Paredes, 2018 , 564 y ss. 
Martínez, 2018).

Por las dificultades de financiación ahora apuntadas, el apoyo de la Administración deviene esencial en España para el éxito de los proyectos co-housing ${ }^{40}$. La cuestión es hasta qué punto la Administración debería involucrarse en estas experiencias. A nivel doctrinal (Viela Castranado, 2018) se defiende en este modelo de co-housing una comunidad de titularidad pública, que financie la adquisición del suelo y la construcción de las viviendas y que controle el ingreso de sus miembros. Sin llegar a una participación tan directa de la Administración, el colectivo La Borda (Miró i Acedo y Fernández Montes, 2016) reclama el establecimiento de ayudas directas a las aportaciones iniciales de los socios, bonificaciones en el Impuesto de Bienes Inmuebles y por eficiencia energética que permitan tener una mayor capacidad para repagar el préstamo hipotecario y la recuperación de las ayudas a la promoción de vivienda de nueva construcción, que puedan ser gestionadas por las cooperativas, lo que ya se tiene presente a nivel municipal ${ }^{41}$.

En este sentido, el derecho comparado ofrece ejemplos que acreditan tanto una participación directa como indirecta de la Administración en las experiencias co-housing. Así, en Suecia son las empresas públicas de vivienda (Familjebostäder) las que financian la construcción en colaboración con las asociaciones sin ánimo de lucro o asociaciones cooperativas (Mogollón García y Fernández Cubero, 2016). Otras experiencias muestran que las asociaciones de vivienda sin ánimo de lucro (non-profit housing associations), como las cooperativas, se benefician en Suiza (Balmer y Gerber, 2018) del apoyo público en forma de incentivos fiscales (por ejemplo, exenciones en el impuesto en la transmisión de la propiedad), garantías bancarias o servicios de asesoramiento. Con todo, la ausencia de subvenciones motiva que en Suiza las viviendas ofrecidas en régimen cooperativo no sean asequibles para las familias de bajos ingresos (Balmer y Gerber, 2018).

La política de vivienda y suelo en España ha priorizado tradicionalmente la propiedad frente al alquiler (incluso para los sectores sociales más desfavorecidos) y la construcción de vivienda, lo que ha originado una presencia escasa de alquiler (y de las cooperativas de viviendas en régimen de cesión de uso) y una actividad de rehabilitación residencial muy por debajo del resto de países europeos (Bazaga Fernández, 2015). Con todo, a nivel estatal se han dado los primeros pasos para apoyar el co-housing. El Plan Estatal de Vivienda 2018-2021 $1^{42}$ prevé, como novedad respeto al anterior plan ${ }^{43}$, ayudas específicas para las cooperativas en régimen de cesión de uso. Así, se prevén ayudas en el marco de la construcción de viviendas para su cesión en alquiler o en uso para las cooperativas de autoconstrucción y las empresas de economía social (art. 26.1.c) y en el marco del fomento de la construcción de viviendas para personas mayores para ser explotadas en alquiler o en cesión de uso para las cooperativas de autoconstrucción y las empresas de economía social (art. 67.1.2). Por lo tanto, las cooperativas en régimen de cesión de uso, en tanto que empresas de economía social ${ }^{44}$, pueden acceder a ayudas públicas para la construcción de viviendas en general o para el co-housing para mayores en particular, cuyo destino y gestión corresponderán a las Comunidades Autónomas. Por otra parte, el RDL 7/2015 prevé de manera general la reserva de suelo para vivienda sujeta a un régimen de protección pública, como podría ser la gestionada por las cooperativas de vivienda de cesión de uso (30\% de la edificabilidad prevista en suelo rural y un $10 \%$ del suelo urbanizado sometido a reforma o renovación, art. 20.1.b), pero es una medida que a la postre deben recoger las normativas autonómicas para que luego puedan aplicarse a nivel local (Muñoz Pérez, Palmero Iglesias y Farinós, 2018) ${ }^{45}$.

En el último apartado se reflexiona sobre el rol de la Administración en el apoyo de experiencias cohousing.

\subsection{La cultura de la vivienda en propiedad y el estado del bienestar}

Los españoles desean ser propietarios de una vivienda. Esta preferencia viene motivada por las políticas

40 Su ausencia ha llevado al abandono de proyectos de co-housing para mayores en España. Así ha sido el caso de Housekide en el País Vasco. Las razones pueden consultarse en: https://sites.google.com/site/housekide/ (última visita 23 de noviembre de 2018).

41 Ver en este sentido las medidas previstas en el Plan para el derecho a la vivienda de Barcelona 2016-2025 ya citado para fomentar las cooperativas de vivienda de cesión de uso, 69 y 70.

42 Real Decreto 106/2018, de 9 de marzo, por el que se regula el Plan Estatal de Vivienda 2018-2021 (BOE 10 marzo 2018, núm. 61, p. 28868)

43 Real Decreto 233/2013, de 5 de abril, por el que se regula el Plan Estatal de fomento del alquiler de viviendas, la rehabilitación edificatoria, y la regeneración y renovación urbanas, 2013-2016 (BOE 10 abril 2013, núm. 86).

44 De acuerdo con el art. 5.1 de la Ley 5/2011, de 29 de marzo, de Economía Social (BOE 30 marzo 2011, núm. 76, p. 33023).

45 Estas reservas "consisten en destinar determinados terrenos para la promoción de viviendas sujetas a algún régimen de protección pública, aunque su origen no ha sido en modo alguno pacífico", 9. Así, a nivel autonómico, en Cataluña el art. 2.1.j de la Ley de Vivienda 18/2007, de 23 de diciembre (BOE 26 enero 2009, núm. 22, p. 8688) busca potenciar la participación de las cooperativas de viviendas y de las entidades de carácter social y asistencial en las políticas de vivienda. Así se ha hecho a través del Decreto 75/2014, de 27 de mayo, que regula el Plan para el derecho a la vivienda (DDOGC 29 mayo 2014, núm. 6633), que contempla la cesión de uso como una fórmula intermedia para acceder a las viviendas de protección oficial (art. 54.1.c). 
públicas de vivienda de las últimas décadas, que han priorizado la vivienda en propiedad para que los ciudadanos acumulen riqueza para sustentar su propio bienestar ("asset-based welfare") ${ }^{46}$. Ante las dificultades para acceder a una vivienda en propiedad, la tenencia inmobiliaria alternativa en España, el alquiler, no ofrece la necesaria asequibilidad, estabilidad y seguridad al arrendatario desde la reforma de la LAU por la Ley 4/2013 (Nasarre Aznar, 2015) y por el Real Decreto-ley 7/201947. Así, los arrendatarios lo son más por necesidad que por voluntad propia. Un estudio de Fotocasa refleja en este sentido que un $47 \%$ de los jóvenes entre 18 y 34 años de edad tienen la intención de comprar una vivienda, una cifra similar al segmento de edad de 25 a 44 años, y que vuelve el dogma de que alquilar es tirar el dinero (Fotocasa, 2018). No es de extrañar, por lo tanto, que la vivienda donde reside la persona mayor sea la principal opción para la jubilación por encima de la vivienda de sus hijos o familiares o una residencia (UDP/Simple Lógica, 2015). Sin embargo, cabe destacar que una vivienda en urbanización compartida y gestionada con zonas y servicios comunes (co-housing) se consideraba como la principal alternativa a una vivienda propia.

El acceso a una cooperativa de cesión de uso implica para las personas jóvenes renunciar a adquirir una vivienda, y para las personas mayores, en ocasiones, la venta de la propia vivienda para poder sufragar los costes de entrada. Esta ausencia de riqueza inmobiliaria puede tener ulteriores repercusiones ante la incierta evolución del sistema público de pensiones en España en el corto plazo atendiendo al actual contexto socioeconómico, principalmente por el paulatino aumento de las personas mayores y el declive de la natalidad y por el progresivo descenso de las provisiones económicas del Fondo de Reserva de la Seguridad Social (Simón Moreno, 2018). Las cooperativas de viviendas tienen algunas ventajas respecto al alquiler en el marco del asset-based welfare: parte de la cuota mensual se destina en ocasiones a un fondo que, actuando como un fondo de pensiones, puede devolver intereses a los 30 años (Etxezarreta, Cano y Merino, 2018) ${ }^{48}$, cabe la posibilidad de que la cooperativa destine un fondo para atender determinadas necesidades de los socios y la cuota inicial se les devuelve cuando causan baja de la cooperativa, lo que les permite obtener cierta liquidez. Pero lo cierto es que las cooperativas no consiguen crear riqueza inmobiliaria individual sino colectiva, por lo que el pago de una suma de dinero por el uso de la vivienda por el socio cooperativista no le implica ninguna riqueza inmobiliaria valorable económicamente.

Este hecho, como se analizará en el último apartado, es una desventaja para los socios de la cooperativa.

\subsection{La potencial "replicabilidad" del modelo}

Es un hecho que las experiencias co-housing están en auge en nuestro país, pero debemos preguntarnos hasta qué punto es un modelo de acceso a la vivienda que pueda "replicarse" fácilmente. A este concepto hace referencia indirectamente el art. 89.3 Ley 27/1999 al prever la posibilidad de cesión o permuta del derecho de uso y disfrute de la vivienda o local con socios de otras cooperativas de viviendas que tengan establecida la misma modalidad. En este sentido, varios son los problemas detectados para la potencial "replicabilidad" de las experiencias co-housing articuladas mediante cooperativas de viviendas en régimen de cesión de uso:

a) El primero es la puesta en funcionamiento de la cooperativa. Así, una de las críticas vertidas a otros modelos de vivienda colaborativa presentes en otros países, como el Community Land Trusts y el modelo alemán Syndikat, es el hecho de que todavía son iniciativas a pequeña escala y, por lo tanto, que solo benefician a una cantidad limitada de personas ${ }^{49}$. Además, el hecho de que el co-housing no sea una alternativa inmediata sino a medio o largo plazo es un hándicap para el desarrollo del cohousing para mayores en España (Vives Barceló, 2016), lo que es extrapolable al resto de experiencias co-housing. También encontramos los mismos problemas en el modelo cooperativo francés (Devaux, 2017): el tiempo que tarda en cristalizar el proyecto colaborativo implica, por un lado, que aquellos que tengan una necesidad inmediata de vivienda (por ejemplo, personas mayores) opten por otras vías, y, por otro, que los potenciales conflictos para llegar a un acuerdo pueden desincentivar la inversión de los socios e inversores. El impulso de las cooperativas también se resiente si no existe un apoyo profesional que ayude a definir los aspectos arquitectónicos y económicos del proyecto. Aquí cabe destacar la figura del project manager en el derecho comparado, que ofrece asesoramiento en el proceso de creación y consolidación de los proyectos (Mogollón García y Fernández Cubero, 2016).

b) En segundo lugar, el necesario cumplimiento de algunos requisitos de acceso. Así, las experiencias de co-housing intergeneracional de La Borda en Cataluña o Amaryllis $\mathrm{eG}^{50}$ y Villa Emma ${ }^{51}$ en

46 Ver en este sentido la obra de Dewilde, C. y Ronald, R. (eds.) (2017), que analiza el vínculo entre la vivienda en propiedad y el estado del bienestar en algunos países europeos.

47 Real Decreto-ley 7/2019, de 1 de marzo, de medidas urgentes en materia de vivienda y alquiler (BOE 5 marzo 2019, núm. 55, p. 21007).

48 Así, en la cooperativa La Borda se prevé la constitución de un fondo mutual, que debe permitir desarrollar la acción mutual y de apoyo mutuo en el conjunto de la Cooperativa y de su actividad (apartado 32.4 de sus estatutos).

49 Fuente: http://syndikat.blogsport.eu/files/2012/10/Horlitz_Housing-Beyond-Profit.pdf.

50 http://www.amaryllis-bonn.de/. 
Alemania están abiertas a toda la ciudadanía (en el caso de La Borda, deben cumplir con los requisitos económicos para acceder a las viviendas de protección oficial). En otros modelos, sin embargo, sí existen barreras para acceder a ser miembro de la cooperativa al discriminarse por edad y/o por otras condiciones. Esto puede observarse en particular en las experiencias co-housing para mayores en España, que requieren, por la finalidad específica de la cooperativa, una edad mínima e, incluso, estar en perfecto estado de salud ${ }^{52}$. También ocurre lo mismo en otros países, donde además se discrimina por el género. Así, en Alemania la cooperativa Kölner Beginenhofs ${ }^{53}$ está destinada a mujeres mayores de 50 años que desean vivir conforme a los valores que inspiraron a las beguinas medievales, y en Francia la Maison des Babayagas ${ }^{54}$ está destinada sólo a mujeres mayores de 60 y menores de 30 años. De hecho, en España también existen proyectos que también se centran en otros segmentos específicos de la población, como Brisa Canarias respecto a las personas con discapacidad ${ }^{55}$

c) Y, en tercer lugar, las dificultades expuestas para formar parte de las cooperativas de vivienda y la financiación requerida pueden desembocar en algunas externalidades negativas del modelo, como la homogeneidad social, étnica e ideológica de los socios y la exclusión del modelo de aquellas familias con pocos ingresos (Chiodelli y Baglione, 2014). De hecho, las experiencias co-housing danesas (Jakobsen y Gutzon Larsen, 2018) apuntan a que el estado socioeconómico de los miembros de la comunidad es mejor que el promedio de la población, a que su nivel de educación se distingue inequívocamente de la población danesa en general (por ejemplo, el 44\% de los encuestados había completado un máster o un doctorado) y a que el creciente carácter multicultural de la sociedad todavía no había llegado con carácter general a estas comunidades. Y en el caso de España, las personas mayores que muestran interés por el co-housing para mayores suelen compartir una estabilidad económica, un cierto nivel cultural (medio-alto) y una conciencia social más o menos elaborada (Torío López, Viñuela Hernández y García-Pérez, 2018), lo que puede predicarse, en general, de los modelos co-housing (Tummers, 2016) ${ }^{56}$.

\section{Las cooperativas de viviendas en régimen de cesión de uso: ¿una alternativa a la vivienda en propiedad o en alquiler?}

El co-housing, como una forma de vivienda colaborativa, requiere de una serie de requisitos objetivos (una serie de elementos privativos y de servicios comunes, cuya titularidad puede ser pública o privada), subjetivos (la participación activa de las personas en la comunidad, que pueden pertenecer a un segmento determinado de la población) y de organización (por ejemplo, en la toma de decisiones) que, por su generalidad, permiten el desarrollo de experiencias co-housing con diferentes fórmulas asociativas, como las cooperativas o las sociedades de responsabilidad limitada. El modelo mayoritariamente acogido en España, el de cooperativas de viviendas en régimen de cesión de uso, es el que mejor se acomoda a los ideales del cohousing por la búsqueda de un ánimo de lucro de las sociedades de responsabilidad limitada y por la pérdida de los valores que inspiran el co-housing en el régimen de propiedad horizontal. La preferencia por el régimen cooperativo, por lo tanto, obedece a razones estructurales: sólo un cambio profundo de la legislación en vigor podría ayudar a estructurar el co-housing con otras fórmulas jurídicas y societarias.

Sin embargo, los problemas detectados afectan a la potencial replicabilidad de las cooperativas de viviendas y deben ser abordados para que puedan convertirse por derecho propio en una alternativa a la vivienda en propiedad y en alquiler, es decir, que puedan crear un tercer mercado de tenencia inmobiliaria. A continuación se profundiza en estos aspectos.

\subsection{Aspectos jurídicos}

El primer problema detectado para el éxito de las cooperativas de viviendas en régimen de cesión de uso es

51 http://www.villa-emma-bonn.de/.

52 Se exige en este sentido tener más de 50 y menos de 70 años de edad en el momento de formular la solicitud de ingreso (Trabensol, http://trabensol.org); entre 50 y 80 en Profuturo, Valladolid (http://www.profuturovalladolid.com); o más de 50 años y estar en perfecto estado de salud (Residencial Santa Clara, https://residencialsantaclara.es).

53 https://beginenhof-koeln.de.

54 https://www.lamaisondesbabayagas.eu.

55 http://www.brisascanarias.org.

56 Los proyectos co-housing son llevados en Francia e Italia por individuos con un perfil sociológico determinado y bastante homogéneo: pertenecen a una alta categoría socioprofesional, trabajan en el sector público o en una profesión liberal y tienen un capital cultural y social significativo (Iorio, 2016, para. 50) 
su regulación jurídica, principalmente la ausencia de un régimen específico en la legislación sobre cooperativas y la problemática de la naturaleza jurídica del derecho por el que se cede el uso al socio de la cooperativa. De esta manera, es necesaria una regulación específica de este modelo en la legislación de cooperativas que clarifique no sólo la naturaleza del derecho de uso sino también las relaciones entre los socios usuarios de la vivienda y la cooperativa, que acaban por resolverse, en algunos casos, por vía estatutaria ante la ausencia de una normativa de referencia. Así, por un lado, la indeterminación de la naturaleza jurídica del derecho puede implicar la "recalificación" judicial de la cesión en un derecho de naturaleza real o personal en función de lo que se haya acordado en los contratos formalizados al efecto con el socio $^{57}$.

Además, algunas cuestiones sin resolver por la legislación vigente son, por ejemplo, la siguientes:

a) Si podría exigirse al usuario alguna caución o garantía (real o personal) que garantizase el pago de la cuota mensual para tener derecho a usar la vivienda.

b) Cómo podría articularse registralmente la inscripción del derecho del usuario en el Registro de la Propiedad y como jugaría entonces, primero, la distribución de responsabilidad hipotecaria del préstamo hipotecario que grava primero la totalidad del edificio (propiedad de la cooperativa) y luego las diversas fincas (viviendas) resultantes cuyo uso se adjudica posteriormente a cada socio, y, segundo, el potencial embargo del derecho de uso y posterior adjudicación a terceros ajenos a los intereses de la cooperativa.

c) Quién debería hacerse cargo de los impuestos y del coste de los seguros asociados a la vivienda.

d) Si podrían prohibirse la realización de determinadas actividades en la vivienda más allá de no poder utilizarla con fines empresariales o qué sucedería si el usuario no utilizase efectivamente la vivienda como residencia permanente.

e) Si el usuario debería hacerse cargo de todas las reparaciones ordinarias y extraordinarias, como se extrae de algunos estatutos, si únicamente tiene la condición de usuario.

f) Si el socio cooperativista podría exigir la realización de obras de accesibilidad en el edificio como sí está habilitado el propietario en una comunidad de vecinos de acuerdo con el art. 10.1 de la Ley 49/1960, de Propiedad Horizontal.

g) Si las mejoras útiles que incrementan el valor de la vivienda o las suntuarias realizadas por el usuario son o no reembolsables cuando se da de baja de la cooperativa.

h) Cómo podrían articularse las relaciones entre los distintos usuarios de la vivienda y la cooperativa en determinados supuestos, por ejemplo, si se atribuye el uso de la vivienda a uno de ellos como consecuencia de una separación, divorcio o nulidad del matrimonio (arts. 90 y 96 CC y 233-20 CCC) viéndose obligado el otro cónyuge a abandonar la vivienda.

i) A todo ello cabe añadir que, si bien la Ley 27/1999 establece que los socios de la cooperativa sólo responderán por sus aportaciones, es posible que los socios adopten, por unanimidad, la decisión de realizar aportaciones adicionales si la cooperativa no puede hacer frente a las deudas pendientes (Agüero Ortiz y Lérida Nieto, 2015) $)^{58}$.

Todas estas cuestiones deberían tratarse en una regulación específica de las cooperativas en régimen de cesión de uso.

Por otra parte, una reforma de legislación vigente podría articular la cesión del uso de la vivienda a través de un contrato de arrendamiento adaptado a las necesidades de la cooperativa y del usuario. Esto implicaría partir de una concepción distinta a como está regulado el contrato de arrendamiento en la LAU. En este sentido, el modelo básico de las cooperativas de vivienda en Alemania se basa en el alquiler ${ }^{59}$, que presenta algunas diferencias respecto al resto de alquileres residenciales (por ejemplo, el arrendatario cooperativo tiene el derecho a defender sus propios intereses en la junta general, y cada miembro puede participar activamente en la cooperativa), y algunas similitudes, por ejemplo gozan de la misma estabilidad y del mismo régimen en cuanto a la conservación de la vivienda, y el arrendatario tampoco puede usualmente subarrendarla sin permiso. En este sentido, doctrinalmente (Nasarre Aznar, Simón Moreno y Molina Roig, 2018) se han analizado unos principios que podrían inspirar una nueva regulación de los arrendamientos urbanos en Cataluña, que también podrían inspirar una reforma de la vigente LAU. Estos principios permiten pactar un contrato de arrendamiento en línea con los países europeos donde el arrendamiento es una alternativa a la vivienda en propiedad (Suiza, Alemania y Austria) y se caracteriza por permitir la

\footnotetext{
57 Así ha tenido lugar en Alemania (Cornelius y Rzeznik, 2014), donde la legislación de cooperativas (Genosssenschaftsgesetz) regula las relaciones entre la cooperativa y los socios como miembros, pero no el contrato que les legitima a usar las viviendas. Este contrato se ha calificado por la jurisprudencia como de arrendamiento y se rige, con alguna adaptación, por las mismas reglas que los alquileres en el mercado privado (aunque también puede concederse al socio un derecho próximo al de propiedad).

58 Quienes además recuerdan la posibilidad del riesgo de que algunos socios decidan no aportar estos recursos adicionales.

59 http://www.dbrunner.de/pub/OTB Working papers 2014-07 German cooperatives.pdf.
} 
formalización de contratos de arrendamiento de larga duración (lo que es compatible con la cesión de uso "indefinido"), que coexistiría con un arrendamiento de carácter temporal de cinco años de prórroga forzosa, la posibilidad de subarrendar la vivienda de manera general, el establecimiento de un sistema de control de rentas y un régimen de corresponsabilidad entre el propietario y el arrendatario en cuanto al régimen de las obras.

\subsection{Aspectos financieros y la involucración de la Administración}

Desde el punto de vista económico, en la cooperativa de cesión de uso se establecen unos requisitos de entrada (la financiación requerida para el inicio de los proyectos) y un pago mensual por el uso de la vivienda. De este modo, la cooperativa puede clasificarse en el continuum de tenencias inmobiliarias como una tenencia intermedia, a medio camino entre el alquiler (público y privado) y la vivienda en propiedad, destinada por lo tanto a familias con ciertos recursos ${ }^{60}$. De hecho, las propias cooperativas de cesión de uso (como la cooperativa Convivir, destinada a las personas de la tercera edad) ${ }^{61}$ dejan claro que se necesitan unos ingresos mínimos para poder formar parte de la cooperativa. Por la necesidad de contar con una financiación inicial y unos ingresos mensuales mínimos, la población a la que se dirigen las cooperativas en cesión de uso puede preferir otras formas de tenencia inmobiliaria, como la vivienda en propiedad, que también requiere un esfuerzo económico inicial, o el alquiler, mucho más asequible en un inicio.

Es por este esfuerzo económico que se ha reclamado una mayor involucración de los poderes públicos para el éxito de este modelo, que ya puede observarse a nivel estatal con el nuevo Plan Estatal de Vivienda y a nivel municipal con la cesión del derecho de superficie sobre suelo de propiedad municipal. Ahora bien, ¿hasta qué punto la Administración local debería apoyar proyectos co-housing que discriminen por segmentos de la población? Y dado que este modelo no tiene per se un carácter social (en el sentido de estar destinado únicamente a las personas con pocos recursos, pues ello depende del criterio de la cooperativa), ¿debería la Administración local ceder el uso del suelo cuando los potenciales usuarios no cumplen los requisitos para ser adjudicatarios de vivienda social? Si este fuera el caso, la Administración debería establecer los debidos mecanismos de fiscalización de la actividad de la cooperativa.

En cuanto al uso del derecho de superficie, el uso de la propiedad temporal o de la propiedad compartida (que, como se ha dicho, se regulan en Cataluña desde 2015) podría ser una alternativa para la cooperativa. La primera confiere a su titular el dominio de un bien durante un plazo cierto y determinado, vencido el cual el dominio hace tránsito al titular sucesivo (art. 547-1 CCC), y la segunda confiere a uno de los dos titulares, llamado propietario material, una cuota del dominio, la posesión, el uso y el disfrute exclusivo del bien y el derecho a adquirir, de modo gradual, la cuota restante del otro titular, llamado propietario formal (art. 556-1 CCC). Por lo tanto, ambas formas de propiedad permiten la adquisición temporal o gradual del dominio. Es cierto que su uso por parte de los socios para la adquisición de la vivienda alejaría a la cooperativa de los principios que rigen el co-housing, aunque estas tenencias intermedias podrían ser útiles en la búsqueda de financiación (Viela Castranado, 2018, 423-424 y 445 y ss.). De esta forma, ambas se podrían utilizar para la adquisición del suelo. En el caso de la propiedad temporal, la cooperativa sería considerada la única propietaria del suelo y de lo que se construyera encima de él durante el plazo pactado (entre 10 y 99 años), sin necesidad de separar ambas titularidades como tiene lugar con el derecho de superficie. En el caso de la propiedad compartida, la cooperativa podría adquirir gradualmente la propiedad del suelo gozando de las facultades de uso y disfrute.

Por otra parte, si la Administración fuera un paso más allá que la cesión del suelo y decidiera construir ella misma las viviendas, debería tener en cuenta el riesgo de que el espíritu solidario y el uso de los elementos comunes quedase en la propia cooperativa, pasando a considerarse de facto como una gated community. En el caso de Suecia, por ejemplo, el estudio de algunas experiencias co-housing (Mogollón García y Fernández Cubero, 2016) muestra que si bien existe un apoyo de las empresas municipales de vivienda (quien construye y es propietaria de las viviendas), ello no se traduce en la mayoría de los casos en una relación activa de los socios de la cooperativa con el resto de la comunidad.

En relación a la introducción de otras medidas favorables al co-housing (como los incentivos físcales) debería realizarse en el marco de un debate profundo sobre los modelos de tenencia inmobiliaria que deberían priorizar los poderes públicos y la finalidad a la que deberían responder. En el caso de las cooperativas, su constitución podría obedecer a distintas finalidades, como la autoconstrucción de viviendas para conseguir mejorar la calidad de espacio público, la regularización de la tenencia de los edificios

\footnotetext{
60 Sobre el continuum de tenencias inmobiliarias, en las que se incluyen la propiedad temporal y la propiedad compartida, ver Nasarre Aznar, 2017.

61 "No atendemos a personas en riesgo de exclusión social, ni somos fundaciones filantrópicas, ni atendemos a personas en estado de marginación. Se necesitan unos ingresos medios para poder pagar los gastos mensuales que se ocasionan. No somos empresas de inserción, ni centros especiales de empleo". Así se posicionaba Víctor J. Gómez Pérez, en la Jornada sobre Consumo cooperativo y colaborativo de vivienda sostenible: aspectos fiscales (2017), cuyos resúmenes pueden encontrarse en http://eprints.ucm.es/43988/1/Grau-vivienda\%20sostenible.pdf. (última visita 23 de noviembre de 2018).
} 
ocupados, la promoción de vivienda autogestionada (en propiedad), el acceso a una vivienda de calidad para familias de clase media, personas jóvenes, madres solteras o personas con discapacidad, ser una vía para tratar el envejecimiento de la población o abordar problemas de asequibilidad e inclusión social (Chiodelli y Baglione, 2014). ¿Deberían, por lo tanto, tener igual trato todas las experiencias co-housing con independencia de su finalidad?

Finalmente, también podría potenciarse la involucración de las entidades bancarias tradicionales en este modelo, lo que ayudaría a la financiación de más proyectos sin tanta dependencia de la banca ética. Se podrían incorporar nuevos valores (como el medio ambiente y la conciencia social) para conseguir financiadores sostenibles y verdes incentivando las denominadas "hipotecas verdes" en la línea, por ejemplo, de la Climate Bonds Initiative ${ }^{62}$ A nivel español, el Senado introdujo durante la tramitación del Proyecto de Ley reguladora de los contratos de crédito inmobiliario ${ }^{63}$ una nueva Disposición adicional decimotercera sobre el crédito verde, como medida de apoyo y fomento en eficiencia energética y uso de fuentes de energía renovable en edificios ${ }^{64}$, que finalmente no se incluyó en el articulado final de la Ley. Con todo, el legislador debería potenciar el uso de estas hipotecas verdes, que podrían facilitar el acceso a financiación a las cooperativas en régimen de cesión de uso.

\subsection{Aspectos sociológicos y de configuración del modelo}

Otros aspectos de interés son de índole sociológico y de configuración del modelo.

En el primer caso, la cooperativa de viviendas en cesión de uso no logra la misma generación de riqueza individual que la vivienda en propiedad para hacer frente a necesidades futuras, a pesar de que existen medidas que mejoran el tratamiento del alquiler (como la posibilidad de recuperar el capital aportado en caso de baja). Por lo tanto, este modelo se encuentra a medio camino entre la propiedad y el alquiler como mecanismo de generación de riqueza individual. Debe tenerse en cuenta que la propiedad de la vivienda juega un papel esencial en la posibilidad de obtener liquidez de la propiedad inmobiliaria. Así sucede con la hipoteca inversa (regulada en la Disposición Adicional $1^{\text {a }}$ de la Ley $41 / 2007^{65}$ ), que pueden solicitarla las personas de edad igual o superior a 65 años propietarias de una residencia habitual libre de cargas. Otras vías al alcance de la persona mayor necesitada de recursos, como el contrato de renta vitalicia (art. 1802 CC) o la propiedad temporal (art. 547.1 CCC), también requieren de la propiedad de una vivienda. En su ausencia, y en un contexto menguante del estado del bienestar, ¿estarían preparados los socios cooperativistas de un senior co-housing para un aumento inesperado de los gastos (por ejemplo, de atención médica) o para una disminución de sus ingresos (por ejemplo, por las pensiones que pudieran recibir)?

En el segundo caso, la ausencia de una cultura cooperativista, de asociacionismo y de toma de decisiones grupales también son obstáculos para el triunfo de la vivienda colaborativa (Mogollón García y Fernández Cubero, 2016), así como la búsqueda de personas interesadas en participar en el proyecto, que pueden pertenecer a un segmento determinado de la población, y el tiempo que se tarda en ponerlo en marcha. De hecho, si bien las personas mayores de edad, las familias monoparentales, las personas con discapacidad física o las familias jóvenes, mujeres o personas mayores que pertenecen al colectivo LGTBI ${ }^{66}$ son los potenciales grupos o segmentos de la población candidatos a formar parte de experiencias co-housing, la realidad muestra que el senior co-housing es el modelo que está teniendo más éxito en España ${ }^{67}$, mientras que el co-housing intergeneracional plantea mayores problemas de implementación debido a los factores apuntados (por ejemplo, financieros).

Los aspectos de configuración del modelo afectan a la potencial "replicabilidad" del modelo, es decir, que su uso pueda generalizarse e incrementar su presencia como forma de tenencia inmobiliaria de la población española, si bien un asesoramiento y profesionalización en la fase de constitución de la cooperativa y en su

62 https://www.climatebonds.net. Es una organización internacional que promueve la inversión en proyectos y activos necesarios para una transición rápida hacia una economía con baja emisión de carbono y resiliente al clima. En el ámbito de los edificios residenciales, la obtención de una "Certificación de Bonos Climáticos" implica que el uso de los fondos será para proyectos verdes, por ejemplo en la inversión en edificios de bajas emisiones o de cero emisiones.

63 BO de las Cortes Generales, 14 febrero 2019, Núm. 12-7, pág 1.

64 El crédito verde se definía como la garantía real establecida sobre un bien susceptible de ser inscrito en un registro de la propiedad que se otorgue en garantía para el repago de una financiación que tuviera por finalidad, básicamente, la mejora permanente de un inmueble que sirve para reducir el consumo o la demanda de agua o energía, y gozaba de los privilegios del crédito refaccionario con la posibilidad de anotarse preventivamente en el Registro de la Propiedad sin necesidad del otorgamiento de escritura pública.

65 BOE 8 diciembre 2007, núm. 294, p. 50593.

66 De acuerdo con la enumeración de Viela Castranado, 2018, quien también plantea los problemas específicos de estos grupos, como la edad de las personas mayores, la rebeldía y posible falta de independencia de las personas jóvenes o el grado de autonomía de las personas con discapacidad física.

67 El Proyecto MOVICOMA ha elaborado un mapa de viviendas colaborativas de mayores según la fase en la que se encuentran, contabilizando cerca de 30 proyectos. Ver http://movicoma.blogs.uoc.edu (última visita 23 de noviembre de 2018). A nivel europeo también existen experiencias que han obtenido buenos resultados en el senior co-housing como forma innovadora de acceso a la vivienda. Así concluye Labit (Labit, 2015) después de exponer los diferentes estudios sobre el tema, si bien puntualiza que el "Co-housing can thus be said to be an innovative option likely to help people age well, given that certain factors such as the composition of the group, architecture, financial and social considerations are taken well into account right from the conception stage". 
gestión posterior, una mayor pedagogía e información al alcance del ciudadano sobre sus características y potenciales beneficios y unas medidas que pudieran prever de antemano posibles necesidades de los cooperativistas (como las apuntadas de las personas mayores) podrían ayudar a incrementar el número de las experiencias co-housing en España, cuyo éxito ya ha quedado demostrado en el senior co-housing.

\subsection{Las cooperativas de viviendas en régimen de cesión de uso en el continuum de tenencias inmobiliarias}

La búsqueda de nuevas formas de tenencia inmobiliaria que sean un continuum entre el alquiler y el pleno dominio (Monk y Whitehead, 2010) debe otorgar a sus usuarios la debida estabilidad en la tenencia, flexibilidad, asequibilidad y seguridad jurídica. La cooperativa de viviendas en cesión de uso presenta las siguientes características dentro del continuum de tenencias inmobiliarias:

a) En primer lugar, otorga una mayor estabilidad en la tenencia que el alquiler gracias a su carácter vitalicio y una menor que la propiedad, que tiene ordinariamente una naturaleza perpetua (hasta que se extinga el derecho por diversas causas, por ejemplo por la destrucción de la vivienda o su expropiación).

b) En segundo lugar, ofrece una flexibilidad similar al alquiler ya que el usuario puede darse de baja de la cooperativa sin restricciones, aunque deba esperar un plazo de tiempo (por ejemplo, seis meses), y una mayor que en la vivienda en propiedad por las mayores dificultades en esta modalidad de tenencia a la hora de vender la vivienda a terceros.

c) En tercer lugar, este modelo parece ofrecer (a falta de estudios económicos al respecto) una asequibilidad inferior al alquiler y similar a la propiedad en el corto plazo (por los requisitos económicos para formar parte de la cooperativa), pero una mayor asequibilidad que el alquiler en el largo plazo (una vez se amortiza el préstamo hipotecario).

d) Finalmente, este modelo ofrece una seguridad jurídica inferior que la propiedad y el alquiler por la ausencia de un régimen jurídico específico de referencia.

Por lo tanto, este modelo podría competir con las tenencias inmobiliarias tradicionales con un marco jurídico y fiscal apropiado, y siempre que se aborden los problemas detectados en el presente trabajo.

\section{A modo de conclusión}

Las experiencias exitosas del co-housing en nuestro país muestran que la cooperativa de viviendas en régimen de cesión de uso, como una modalidad de la vivienda colaborativa, puede llegar a competir con las tenencias inmobiliarias tradicionales en términos de estabilidad, flexibilidad y asequibilidad (en el largo plazo), y puede ser útil para los distintos colectivos sociales.

Así, y más allá de los valores y los principios que inspiran este modelo, el co-housing puede ser una vía para abordar los problemas de asequibilidad que sufren los jóvenes y las familias españolas para acceder a una vivienda y el progresivo envejecimiento de la población española, que podría contar con unas viviendas adaptadas a sus necesidades (debe tenerse en cuenta que sólo el $0,6 \%$ de las viviendas españolas son universalmente accesibles ${ }^{68}$ y que más de 100.000 personas en España no salen nunca de casa por la falta de accesibilidad de sus viviendas ${ }^{69}$ ). El co-housing también podría ayudar a integrar socialmente y a encontrar apoyo mutuo a determinados colectivos vulnerables, como el de mayores LGTBI, a la gente afectada por una discapacidad física o psíquica y a sus familiares, que podrían disfrutar de una vivienda y entorno adaptados a sus necesidades, a la autoconstrucción de viviendas con criterios de sostenibilidad para conseguir mejorar la calidad de espacio público, y a revitalizar aquellas áreas que pierden población atrayendo emprendedores que quieran desarrollar sus ideas de negocio o startups.

Por lo tanto, la potenciación del co-housing sería interesante desde un punto de vista social, pero es necesario que se aborden los problemas detectados para que pueda convertirse en una alternativa a la propiedad y al alquiler para el conjunto de la población española. Así, la ausencia de una regulación marco específica de este modelo, los aspectos organizativos y de financiación previos a su constitución, la focalización en segmentos específicos de la población y el rol que juega la vivienda en propiedad en nuestro estado del bienestar son factores que dificultan la replicabilidad del modelo y que deberían abordarse por los poderes públicos.

\footnotetext{
68 Informe "La accesibilidad de las viviendas en España" de marzo de 2018. Puede hallarse en https://www.fundacionmdp.org/wpcontent/uploads/2018/04/201803-Accesibilidad-viviendas-espana_FundacionMdP-min.pdf (última visita 4 de julio de 2019).

69 Fuente: El País, "100.000 personas no salen nunca de casa en España por la falta de accesibilidad de sus inmuebles", 12/6/2019, https://elpais.com/sociedad/2019/06/12/actualidad/1560334356 594699.html (última visita 4 de julio de 2019).
} 


\section{Referencias bibliográficas}

Abad Segura, E. y Valls Martínez, M. (2018) Análisis de viabilidad de la banca ética en España a través de Triodos Bank. Comparativa económico-financiera con la banca tradicional. REVESCO. Revista de Estudios Cooperativos, Segundo Cuatrimestre, $\mathrm{N}^{\circ} 128$, pp. 7-35. DOI: 10.5209/REVE.60205.

Agüero Ortiz, A. y Lérida Nieto, P. (2015) La cesión de uso de viviendas: ¿es realmente una alternativa habitacional más beneficiosa? Centro de Estudios de Consumo, pp. 1-24. Disponible en: https://previa.uclm.es/centro/cesco/pdf/trabajos/34/100.pdf.

Balmer, I. y Gerber, J-D. (2018) Why are housing cooperatives successful? Insights from Swiss affordable housing policy. Housing Studies, Vol. 33, No 3, pp. 361-385. DOI: 10.1080/02673037.2017.1344958.

Bazaga Fernández, I. (2015) Opinión pública y política de vivienda las actitudes de los españoles sobre la política de vivienda, pp. 1-403. Tesis doctoral. Disponible en: https://eprints.ucm.es/33348/1/T36450.pdf.

Bresson, S. y Denèfle, S. (2015) Diversity of self- managed co-housing initiatives in France. Urban Research \& Practice, Vol. 8, No 1, pp. 5-16. DOI: 10.1080/17535069.2015.1011423.

Cabré, E. y Andrés, A. (2018) La Borda: a case study on the implementation of cooperative housing in Catalonia, International Journal of Housing Policy, Vol. 18, No 3, pp. 412-432. DOI: 10.1080/19491247.2017.1331591.

Chiodelli, F. y Baglione, V. (2014) Living together privately: for a cautious reading of cohousing. Urban Research \& Practice, Vol. 7, No 1, pp. 20-34. DOI: 10.1080/17535069.2013.827905

Consejo de la Juventud de España (2017) Observatorio de Emancipación del Consejo de la Juventud de España, pp. 122. Disponible en: http://www.cje.org/descargas/cje7255.pdf.

Cornelius J. y Rzeznik, J. (2014) National Report for GERMANY. TENLAW: Tenancy Law and Housing Policy in Multi-level Europe, pp. 1-243. Disponible en: http://www.tenlaw.unibremen.de/reports/GermanyReport_09052014.pdf.

Coudroy de Lille, L. (2015) Housing cooperatives in Poland. The origins of a deadlock. Urban Research \& Practice, Vol. 8, No 1, pp. 17-31. DOI: 10.1080/17535069.2015.1011424.

Czischke, D. (2018) Collaborative housing and housing providers: towards an analytical framework of multistakeholder collaboration in housing co-production. International Journal of Housing Policy, Vol. 18, $\mathrm{N}^{\circ} 1$, pp. 5581. DOI: $10.1080 / 19491247.2017 .1331593$.

Devaux, C. (2017) L'habitat participatif: l'immobilier "alternatif'? En: Moulin, J-M. (ed.), Droit de la finance alternative. Bruxelles: Bruylant, pp. 315-334.

De Castro Vítores, G. (2008) Interés particular y poder comunitario en la propiedad horizontal: el criterio de la máxima utilidad del inmueble. Revista Crítica de Derecho Inmobiliario, No 706 , pp. 579-596.

Dewilde, C. y Ronald, R. (eds.) (2017) Housing wealth and welfare. Cheltenham: Edward Elgar Publishing. 288 p.

Eurostat (2018) Distribution of population by tenure status, type of household and income group - EU-SILC survey. Disponible en: https://ec.europa.eu/eurostat/web/products-datasets/-/ilc lvho02.

Etxezarreta, A., Cano, G. y Merino. S. (2018) Las cooperativas de viviendas de cesión de uso: experiencias emergentes en España. CIRIEC-España, Revista de Economía Pública, Social y Cooperativa, № 92, pp. 61-86.

Etxezarreta, A. y Merino. S. (2013) Las cooperativas de vivienda como alternativa al problema de la vivienda en la actual crisis económica. REVESCO. Revista de Estudios Cooperativos, Tercer Cuatrimestre, $\mathrm{N}^{\circ}$ 113, pp. 92-119. DOI:10.5209/rev_REVE.2014.v113.43382.

Fernández Campos, J. A. (1999) La transmisibilidad de los derechos reales de uso y habitación (análisis de los artículos 523 y 525 del Código Civil). Anales de Derecho, No 17, pp. 85-123.

Fotocasa (2018) Radiografía del mercado de la vivienda 2017-2018, pp. 1-25. Disponible en http://prensa.fotocasa.es/wp-content/uploads/2018/05/Radiograf\%C3\%ADa-del-mercado-de-la-vivienda-20172018-BAJA.pdf.

Gallart, A. (2014) Notas sobre el proceso de constitución de una cooperativa de vivienda de cesión de uso en Can Batlló. En: I Congreso Internacional de Vivienda Colectiva Sostenible, Barcelona, 25, 26 y 27 de febrero de 2014. Barcelona: Máster Laboratorio de la Vivienda Sostenible del Siglo XXI (pp. 394-399). Disponible en: http://hdl.handle.net/2099/15341.

Iorio, A. (2018) Le cohousing: un nouveau mode d'habiter? Socio-anthropologie, $\mathrm{N}^{\circ}$ 32, pp. 87-101. Disponible en: http://journals.openedition.org/socio-anthropologie/1909.

Jakobsen, P. y Gutzon Larsen, H. (2018) An alternative for whom? The evolution and socio-economy of Danish cohousing. Urban Research \& Practice, pp. 1-17. DOI: 10.1080/17535069.2018.1465582.

Labit, A. (2015) Self-managed co-housing in the context of an ageing population in Europe. Urban Research \& Practice, Vol. 8, No 1, pp. 32-45.

Lacruz Mantecón, M. (2018) Mi casa no es mía: usufructo, uso y habitación como vías de acceso a la vivienda. En: Alonso Pérez, $\mathrm{M}^{\mathrm{a}} \mathrm{T}$. (dir.), Nuevas vías jurídicas de acceso a la vivienda desde los problemas generados por la vivienda en propiedad ordinaria financiada con créditos hipotecarios a otras modalidades jurídico-reales de acceso a la vivienda. Pamplona: Aranzadi, pp. 285-348.

Lambea Rueda, A. (2012) Códigos de conducta y cooperativas de viviendas. Jornada: Códigos de conducta y economía social: cooperativas de viviendas, pp. 1-14. Disponible en: https://eprints.ucm.es/30467/1/ponencia_cooperativas\%20de\%20viviendas\%20hoy_JornadaCDCyEconomiaSocial 2012.pdf. 
Lambea Rueda, A. (2012a) Adjudicación y cesión de uso en las cooperativas de viviendas: usufructo, uso y habitación y arrendamiento, CIRIEC-España, Revista de Economía Pública, Social y Cooperativa, Nº 23, pp. 1-40.

Lang, R. y Stoeger, H. (2018) The role of the local institutional context in understanding collaborative housing models: empirical evidence from Austria. International Journal of Housing Policy, Vol. 18, No 1, pp. 35-54. DOI: 10.1080/19491247.2016.1265265.

López de la Cruz, L. y Sánchez, J. A. (2017) Las viviendas colaborativas para mayores como modelo habitacional para la promoción del envejecimiento activo. Aspectos sociales y jurídicos. En: López de la Cruz, L. y Sánchez Medina, J. A. (eds.), Soluciones habitacionales para el envejecimiento activo: viviendas colaborativas o cohousing. Respondiendo a los cambios demográficos desde la innovación social. Valencia: Tirant lo Blanch, pp. 121-150.

López de la Cruz, L. y Vázquez-Pastor Jiménez, L. (2015) Nuevos modelos de hábitat compartido: el proyecto cohousing. Del derecho de propiedad al derecho de uso. Revista Aranzadi de derecho patrimonial, $\mathrm{N}^{\circ}$ 38, pp. 253284.

Lucas Esteve, A. (2014) Dret Civil Català Vol. IV (2). Drets Reals. Drets reals limitats i Registre de la Propietat. Barcelona: JM ${ }^{\mathrm{a}}$ Bosch Editor. $418 \mathrm{p}$.

Martínez Charterina, A. (2016) La cooperativa y su identidad. Madrid: Dykinson, 114 p.

Merino Hernández, S. (2013) La cooperativa de viviendas como administradora de bienes comunes. GEZKI, No. 9, pp. 101-110 Disponible en: http://www.ametsaksortzen.eus/wpcontent/uploads/2018/02/20121023_ehu_cooperativaviviendas_12737-46745-1-PB.pdf.

Ministerio de Empleo y Seguridad Social (2017) Informe sobre los jóvenes y mercado de trabajo, pp. 1-46. Disponible en: http://www.empleo.gob.es/es/sec trabajo/analisis-mercado-trabajo/jovenes/numeros/2017/Junio2017.pdf.

Miró i Acedo, I. y Fernàndez Montes, A. (2016) La economía social y solidaria en Barcelona. Barcelona: ICG Marge. $192 \mathrm{p}$.

Molina Roig, E. (2014) National Report for Spain. TENLAW: Tenancy Law and Housing Policy in Multi-level Europe, pp. 1-245. Disponible en: http://www.tenlaw.uni-bremen.de/reports/SpainReport 16092014.pdf.

Mogollón García, I. y Fernández Cubero. A. (2016) Arquitecturas del cuidado. Viviendas colaborativas para personas mayores. Un acercamiento al contexto vasco y las realidades europeas. Zeberio: Emakunde, pp. 1-265. Disponible en:

http://www.emakunde.euskadi.eus/contenidos/informacion/publicaciones_subvencionadas2/es_def/adjuntos/beca.20 15.1.arquitecturas.del.cuidado.pdf.

Monk, S. y Whitehead, C. (2010) Making Housing More Affordable - The Role of Intermediate Tenures. Oxford: Wiley-Blackwell. 328 p.

Muñoz Fernández, G. A. (2017) Juventud y mercado de la vivienda en España: análisis de la situación. Revista de Estudios de Juventud, $\mathrm{N}^{\mathrm{O}} 116, \quad \mathrm{pp} .155-168 . \quad$ Disponible en: http://www.injuve.es/sites/default/files/2018/06/publicaciones/revista116_documentos11.pdf.

Muñoz Pérez, D., Palmero Iglesias, L. y Farinós, J. Ma (2018) Estudio especial de la reserva como técnica urbanística al servicio de la política de vivienda. Valencia: Universitat Politècnia de València. $94 \mathrm{p}$.

Nasarre Aznar, S., Simón Moreno, H. y Molina Roig, E. (2018) Un nou dret d'arrendaments urbans per a afavorir l'accés a l'habitatge. Barcelona: Atelier. 365 p.

Nasarre Aznar, S. (2017) Exposición de motivos de la ley 19/2015. En: Nasarre Aznar. S. (dir.), La propiedad compartida y la propiedad temporal (Ley 19/2015). Aspectos legales y económicos. Valencia: Tirant lo Blanch, pp. 39-58.

Nasarre Aznar, S. (2015) La eficacia de la Ley 4/2013, de reforma de los arrendamientos urbanos, para aumentar la vivienda en alquiler en un contexto europeo. Revista Crítica de Derecho Inmobiliario, No 747, pp. 205-249.

Nasarre Aznar, S. y Simón Moreno, H. (2013) Fraccionando el dominio: las tenencias intermedias para facilitar el

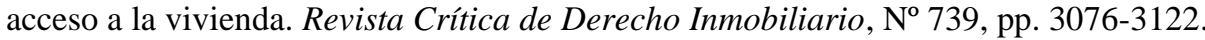

Pastor Sempere, M. C. (2006) Los recursos propios en las sociedades cooperativas. Madrid: Editoriales de Derecho Reunidas.

Sánchez Paredes, M. L. (2018) Las decisiones de los tribunales en torno a la clasificación de los créditos derivados de los préstamos participativos en el concurso de acreedores del prestatario. Revista Crítica de Derecho Inmobiliario, $\mathrm{N}^{\mathrm{o}} 765$, pp. 564-583.

Scanlon, K. y Fernández Arrigoitia, M. (2015) Development of new cohousing: lessons from a London scheme for the over-50s. Urban Research \& Practice, Vol. 8, № 1, 106-121. DOI: 10.1080/17535069.2015.1011430.

Simón Moreno, H. (2018) La optimización de la hipoteca inversa desde la perspectiva europea. Valencia: Tirant lo Blanch. $285 \mathrm{p}$.

Simón Moreno, H. (2011) Propuestas de regulación para habitar parcialmente una vivienda. En Nasarre Aznar, S. (dir.), El acceso a la vivienda en un contexto de crisis. Madrid: Edisofer, pp. 225-248.

Soler Tarradellas, $\mathbf{M}^{\mathbf{a}}$ J. (2017) Análisis económico sobre la accesibilidad a la vivienda: el esfuerzo familiar en las tenencias intermedias. En: Nasarre Aznar, S. (dir.), La propiedad compartida y la propiedad temporal (Ley 19/2015). Aspectos legales y económicos. Valencia: Tirant lo Blanch, pp. 617-648.

Torío López, S., Viñuela Hernández, P. y García-Pérez, O. (2018) Experiencias de vejez vital. Senior Cohousing: autonomía y participación. Aula Abierta, vol. 47, № 1, pp. 79-86.

Tummers, L. (2016) The re-emergence of self-managed co-housing in Europe: A critical review of co-housing research. Urban Studies, Vol. 53, No 10, pp. 2023-2040. https://doi.org/10.1177/0042098015586696. 
UDP/Simple Lógica (2015) El “cohousing” (viviendas colaborativas) y las personas mayores, Informe Mayores UPD, Edición 7, Año III, pp. 1-9. Disponible en: http://ecohousing.es/wp-content/uploads/2016/03/El-cohousing-y-laspersonas-mayores-Informe-UDP-abril-2015.pdf.

Vicent Chuliá, F. (2012) Introducción al Derecho Mercantil, 23ª ed.. Valencia: Tirant lo Blanch.

Viela Castranado, M. (2018) Cohousing: ¿utopía o una posible solución a los problemas habitacionales en nuestro país? En: Alonso Pérez $\mathrm{M}^{\mathrm{a}} \mathrm{T}$. (dir.), Nuevas vías jurídicas de acceso a la vivienda desde los problemas generados por la vivienda en propiedad ordinaria financiada con créditos hipotecarios a otras modalidades jurídico-reales de acceso a la vivienda. Pamplona: Aranzadi, pp. 401-452.

Vives Barceló, M. (2016) Senior cohousing. Una nova alternativa de convivència per a la gent gran. Anuari de l'envelliment. Illes Balears, pp. 400 y 401.

Zaragoza Pascual, G. (2013) Cooperativismo, viviendas para mayores y Servicios Sociales. GEZKI, No 10, pp. 53-70. 